\title{
Article
}

\section{The effects of insulin and short-term hyperglycaemia on myocardial blood flow in young men with uncomplicated Type I diabetes}

\author{
J. Sundell ${ }^{1,2}$, H. Laine ${ }^{1,2}$, P. Nuutila ${ }^{1,2}$, T. Rönnemaa ${ }^{2}$, M. Luotolahti ${ }^{3}$, O. Raitakari ${ }^{1}$, J. Knuuti ${ }^{1}$ \\ ${ }^{1}$ Turku PET Centre, ${ }^{2}$ Department of Medicine, ${ }^{3}$ Department of Clinical Physiology, University of Turku, Turku, Finland
}

\begin{abstract}
Aims/hypothesis. Insulin enhances coronary vasodilation in healthy subjects. We tested whether insulin is able to induce coronary vasodilation in Type I (insulin-dependent) diabetic mellitus patients. Additionally, the effect of short-term hyperglycaemia on myocardial perfusion was studied.

Methods. Myocardial blood flow was quantitated basally and during adenosine infusion $(140 \mu \mathrm{g} / \mathrm{kg}$ per min iv) with or without simultaneous insulin infusion $(1 \mathrm{mU} / \mathrm{kg}$ per $\mathrm{min}$ for $60 \mathrm{~min}$ ) in nine non-smoking Type I diabetic males $\left(\mathrm{HbA}_{1 \mathrm{c}} 7.4 \pm 1.0 \%\right)$ without diabetic complications and 10 healthy non-diabetic otherwise matched males using positron emission tomography and ${ }^{15} \mathrm{O}$-water. Diabetic patients were studied on two occasions, once during normoglycaemia (plasma glucose $\sim 6 \mathrm{mmol} / \mathrm{l}$ ) and once during hyperglycaemia $(\sim 10 \mathrm{mmol} / \mathrm{l})$ induced by reducing the dose of insulin for two days.

Results. Resting myocardial blood flow was similar in the studied groups (NS). Hyperaemic adenosine stim-
\end{abstract}

ulated flow was $23 \%$ lower in diabetic than in nondiabetic subjects $\left(3.09 \pm 0.72\right.$ vs $4.0 \pm 1.13 \mathrm{ml} \cdot \mathrm{g}^{-1} \cdot \mathrm{min}^{-1}$, $p<0.05)$. Insulin increased significantly adenosine stimulated flow by $23 \%$ in diabetic and $17 \%$ in nondiabetic subjects (NS between the groups). Hyperglycaemia for two days had no effect on flow values when compared to the values during normoglycaemia (NS).

Conclusion/interpretation. Insulin has similar vasodilative effects on coronary arteries in diabetic and nondiabetic subjects. Short-term hyperglycaemia does not alter myocardial blood flow or abolish insulin induced vasodilation in these patients. Insulin induced coronary vasodilation might contribute to the known beneficial effect of intensive insulin therapy on myocardial ischaemia in diabetic patients. [Diabetologia (2002) 45:775-782]

Keywords Type I diabetes, myocardial perfusion, coronary vasoreactivity, insulin, hyperglycaemia, positron emission tomography.

tery disease and cardiovascular disease is the leading cause of death in diabetic patients [1]. Most studies in diabetic patients have shown reduced coronary vasoreactivity $[2,3,4]$ due to impaired endothelial function [2]. The previous studies, however, have included patients with both Type I and Type II diabetes [2, 4] or other potentially confounding factors, such as diabetic complications, smoking, hypertension, obesity and lipid abnormalities [2, 3, 4] which are known to also reduce coronary vasoreactivity $[5,6,7,8]$. Therefore, attribution of the found abnormalities in coronary microvascular function of the previous studies to diabetes in itself might be questioned.
Corresponding author: J. Sundell, Turku PET Centre, Turku University Central Hospital, P.O. Box 52, FIN-20521 Turku, Finland, e-mail: jan.sundell@utu.fi

Abbreviations: PET, Positron emission tomography; $\left[{ }^{15} \mathrm{O}\right] \mathrm{H}_{2} \mathrm{O}$, oxygen-15-labeled water; ROI, region of interest; SPECT, single-photon emission computed tomography; $\mathrm{VO}_{2}$, max, maximal aerobic capacity; WBGU, whole body glucose uptake
Received: 21 December 2001 / Revised: 4 February 2002 Published online: 25 April 2002

Type I (insulin-dependent) diabetes mellitus is an important risk factor for the development of coronary ar-

(C) Springer-Verlag 2002 
Insulin induces a dose and time-dependent vasodilation in the peripheral arteries $[9,10,11]$ by a endothelium-dependent mechanism including the L-arginine-nitric oxide pathway $[12,13]$ and the sympathetic nervous system [13]. Insulin induces vasodilation also in myocardial vasculature in healthy humans [14]. In addition to insulin actions on substrate metabolisms $[15,16,17,18]$, insulin-induced coronary vasodilation might contribute to the known beneficial effect of insulin on myocardial ischaemia. Although diabetic patients with acute myocardial infarction especially benefit from intensive intravenous insulin therapy [19], no studies of insulin's vasodilatory effects on myocardial circulation have been done in diabetic patients.

Poor glycaemic control seems to act as an independent risk factor for coronary artery disease in diabetic patients [20, 21, 22, 23]. Chronic hyperglycaemia in Type I diabetes is associated with impaired endothelium-dependent vasodilation $[24,25]$ which might be due to reduced availability of nitric oxide during hyperglycaemia [26].

Positron emission tomography (PET) allows myocardial blood flow and coronary vasoreactivity to be noninvasively measured in humans [27] even though the high costs and limited availability prevent its wider use. PET indicates that coronary vasoreactivity is lower in patients with coronary heart disease (CHD), Type I diabetes, hypertension, and hyperlipidaemias and correlates with the risk factors of CHD even in healthy subjects [28]. The most widely used tracer to measure myocardial perfusion is oxygen-15-labeled water $\left(\left[{ }^{15} \mathrm{O}\right]-\mathrm{H}_{2} \mathrm{O}\right)$ and adenosine induced hyperaemia has been commonly used as a measure of coronary vasoreactivity $[29,30]$.

In this study, we examined the effect of insulin on coronary vasodilation in diabetic patients and whether short-term (2 days) hyperglycaemia alters myocardial flow and coronary vasodilation in diabetic patients. Myocardial blood flow and hyperaemic adenosine stimulated flow with or without simultaneous hyperinsulinaemia were determined after an overnight fast using PET and $\left[{ }^{15} \mathrm{O}\right] \mathrm{H}_{2} \mathrm{O}$. Myocardial perfusion of diabetic patients was studied both during good glycaemic control and during hyperglycaemia.

\section{Subjects and methods}

Subjects. Nine non-smoking otherwise healthy Type I diabetic males (age $33 \pm 8$ years) with good glycaemic control and without any diabetic complications were investigated (Table 1). The duration of diabetes was $15.0 \pm 9.7$ years and $\mathrm{HbA}_{1 \mathrm{c}}$ $7.4 \pm 1.0 \%$. The diabetic patients were followed up for one month before the PET study and the administration of insulin was optimised if needed. The results of the diabetic patients were compared with results of ten non-smoking, non-diabetic otherwise matched healthy men. Echocardiographically determined left ventricular mass, dimensions and function as well
Table 1. Characteristics of the study subjects

\begin{tabular}{|c|c|c|}
\hline & Type I diabetic & Non-diabetic \\
\hline$n$ & 9 & 10 \\
\hline Age (years) & $33(8)$ & $33(8)$ \\
\hline BMI $\left(\mathrm{kg} / \mathrm{m}^{2}\right)$ & $24.9(3.0)$ & $24.6(2.2)$ \\
\hline $\mathrm{VO}_{2} \max \left(\mathrm{ml} \cdot \mathrm{kg}^{-1} \cdot \mathrm{min}^{-1}\right)$ & $35(4)$ & $36(3)$ \\
\hline Blood pressure (mmHg) & $116 / 72(4 / 7)$ & $117 / 66(10 / 8)$ \\
\hline $\mathrm{HbA}_{1 \mathrm{c}}(\%)$ & $7.4(1.0)^{\mathrm{a}}$ & $5.3(0.5)$ \\
\hline Cholesterol (mmol/l) & $4.4(0.9)$ & $5.2(0.7)$ \\
\hline HDL-cholesterol (mmol/l) & $1.4(0.3)$ & $1.5(0.3)$ \\
\hline Triglycerides $(\mathrm{mmol} / \mathrm{l})$ & $0.9(0.5)$ & $1.1(0.5)$ \\
\hline LDL-cholesterol (mmol/l) & $2.7(0.8)$ & $3.2(0.7)$ \\
\hline Apo A-1 (g/l) & $1.61(0.26)$ & $1.51(0.09)$ \\
\hline Apo B (g/l) & $0.87(0.25)$ & $0.93(0.18)$ \\
\hline $\mathrm{Lp}(\mathrm{a})(\mathrm{U} / \mathrm{l})^{\mathrm{b}}$ & $65(57)$ & $178(55)$ \\
\hline
\end{tabular}

$\mathrm{VO}_{2}$ max, maximal aerobic capacity; Apo A-1, apoprotein A1; Apo B, apoprotein B; Lp(a), lipoprotein A

a $p<0.0001$ vs non-diabetic

$\mathrm{b}$ Value expressed as mean (median)

as the stress echocardiographies and electrocardiograms were normal in all studied subjects. Each subject gave a written informed consent. The study was conducted according to the guidelines of the Declaration of Helsinki, and the study protocol was accepted by the Ethics Committee of the Turku University Central Hospital.

Study design. Diabetic patients were studied on two separate days, once during good glycaemic control (plasma glucose: fasting 5-7 mmol/l and postprandial $<9 \mathrm{mmol} / \mathrm{l}$ ) and thereafter during hyperglycaemia for two days (plasma glucose: fasting $10-11 \mathrm{mmol} / \mathrm{l}$ and postprandial $>12 \mathrm{mmol} / \mathrm{l}$ ). Good glycaemic control was achieved by increasing insulin doses if needed. Hyperglycaemia was induced by reducing the intermediate-acting insulin dose by one third for two days. The non-diabetic subjects were studied only once, during normoglycaemia.

PET studies were done after an overnight fast. Additionally, the subjects were instructed to avoid all caffeine containing drinks and foods for $12 \mathrm{~h}$ before the PET studies. In the PET study morning, the normal dose of intermediate-acting insulin was reduced by one third during normoglycaemia and withdrawn during hyperglycaemia and short-acting insulin were withdrawn in both mornings. On each study day myocardial perfusion was measured three times (Fig. 1). The first measurement was done at rest, and the second after administration of adenosine $(140 \mu \mathrm{g} / \mathrm{kg}$ per min for 5 minutes i.v.). Thereafter insulin infusion (Actrapid Human; Novo Nordisk, Copenhagen, Denmark) (1 $\mathrm{mU} / \mathrm{kg}$ per min) [31] was started into the right antecubital vein and continued for $60 \mathrm{~min}$ before the second intravenous infusion of adenosine and the third perfusion measurement. Normoglycaemia (plasma glucose $\sim 5.5 \mathrm{mmol} / \mathrm{l}$ ) or hyperglycaemia (plasma glucose $\sim 10 \mathrm{mmol} / \mathrm{l}$ ) were maintained using a variable rate of $20 \%$ glucose. The rate of the glucose infusion was adjusted according to plasma glucose determinations done every 5 min from arterialized venous blood. Samples for serum insulin and non-esterified fatty acids were taken every $30 \mathrm{~min}$. Whole body glucose uptake was calculated from the glucose infusion rate after correcting for changes in the glucose pool size [31]. Electrocardiogram and heart rate were monitored continuously during the studies. Blood pressure was monitored with an automatic oscillometric blood pressure monitor (OMRON HEM-705C, Omron Healthcare, Hamburg, Germany) during the PET study. 


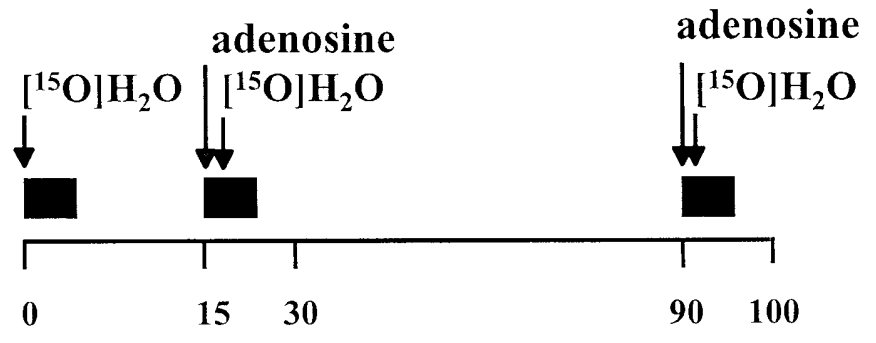

Time (min)

\section{Insulin infusion $\left(1 \mathrm{mU} \mathrm{kg}^{-1} \mathrm{~min}^{-1}\right)$}

\section{$20 \%$ glucose infusion}

Fig. 1. Design of the study. Myocardial perfusion (solid square) was measured with $\left[{ }^{15} \mathrm{O}^{1} \mathrm{H}_{2} \mathrm{O}\right.$ three times: once during basal conditions and two times during adenosine stimulation without and with simultaneous insulin infusion. Insulin was infused at rate $1 \mathrm{mU} \cdot \mathrm{kg}^{-1} \cdot \mathrm{min}^{-1}$

Production $\left[{ }^{15} \mathrm{O}\right] \mathrm{H}_{2} \mathrm{O}$. For production of $15 \mathrm{O}$ a low-energy deuteron accelerator Cyclone 3 was used (Ion Beam Application, Louvain-la-Neuve, Belgium). ${ }^{15} \mathrm{O}$-labelled water was produced using dialysis techniques in a continuously working water module [32]. Sterility and pyrogenity tests for water and chromatographic analysis for gases were done to verify the purity of the products.

Image acquisition, processing and corrections. The subjects were positioned supine in a 15-slice ECAT 931/08-12 tomograph (Siemens/CTI, Knoxville, Tenn., USA). After the transmission scan, myocardial perfusion was measured with an intravenous injection of $\left[{ }^{15} \mathrm{O}\right] \mathrm{H}_{2} \mathrm{O}(\sim 1.5 \mathrm{GBq})$ at rest and $60 \mathrm{sec}$ after each intravenous administration of adenosine. Each dynamic scan lasted for $6 \mathrm{~min}(6 \times 5 \mathrm{~s}, 6 \times 15 \mathrm{~s}, 8 \times 30 \mathrm{~s})$. All data were corrected for deadtime, decay, and photon attenuation and reconstructed into a $128 \times 128$ matrix. Images were processed using a recently developed MRP reconstruction algorithm [33].

Calculation of regional myocardial blood flow. Regions of interest (ROIs) were drawn in the lateral, anterior and septal wall of the left ventricle in four representative transaxial slices in each study as described previously [6]. The ROIs outlined in the baseline images were copied to the images obtained after adenosine administration. Values of regional myocardial blood flow (expressed in $\mathrm{ml} /$ gram of tissue per min) were calculated according to the previously published method using the single compartment model [34, 35]. The arterial input function was obtained from the left ventricular time activity curve using a previously validated method [36], in which corrections were made for the limited recovery of the left ventricular ROI and the spillover from the myocardial signals. The average blood flow of the lateral and anterior part of the myocardium was calculated and used in further analysis.

Retinal photography and sensory nerve function tests. Retinal photography was performed after mydriatic instillation with a Canon CR4-45NM fundus camera (Canong, Kanagawa, Japan) and one $45 \%$ field photograph, including areas of papilla and macula, was taken from each eye. Polaroid photoprints were analysed by one experienced diabetologist (TR). To exclude peripheral neuropathy Semmes-Weinstein monofilament test was used to examine cutaneous pressure sensation of 10 plantar sites on both feet [37].

Echocardiographic examination. To rule out silent ischaemia and cardiomyopathy subjects underwent a rest and a bicycle exercise echocardiographic examination. All echocardiographic recordings and analyses were done by the same experienced investigator (ML) using a commercially available ultrasound scanner (Acuson 128XP/10, Acuson, Mountain View, Calif., USA). Standard echocardiographic views of the left ventricle were obtained and cardiac dimensions were measured first at rest. Thereafter an upright bicycle-ergometer exercise test was done by increasing work load by $20 \mathrm{~W}$ at $1 \mathrm{~min}$ intervals. The test was symptom-limited maximal exercise test and continued until extreme fatigue when at least $90 \%$ of the predicted maximum heart rate was reached. The echocardiograms were recorded before and immediately after the exercise. All subjects had a normal exercise capacity, were asymptomatic, had no diagnostic ST-changes in electrocardiograms and no wall motion disturbances either at rest or immediately after the maximal exercise.

Analytical methods. Plasma glucose was determined by the glucose oxidase method [38]. Serum insulin was measured by radioimmunoassay kit (Pharmacia, Uppsala, Sweden). Serum total cholesterol, high density lipoprotein (HDL) cholesterol and triglyceride concentrations were measured using standard enzymatic methods (Boehringer Mannheim, Mannheim, Germany) with a fully automated analyzer (Hitachi 704; Hitachi, Tokyo, Japan). The low density lipoprotein (LDL) cholesterol concentration was calculated by using the Friedewald formula [39]. Apolipoprotein A-1 (apo A-1) and apolipoprotein B (apo B) were measured by an immunonephelometric method (Behring BNA, Marburg, Germany). The serum lipoprotein(a) (Lp[a]) was determined using a solid-phase two-site immunoradiometric assay (Mercodia Apo(a) RIA; Mercodia AB, Uppsala, Sweden). The first morning urine sample was analysed to define the ratio of urine albumin $(\mathrm{mg} / \mathrm{l})$ to urine creatine concentration ( $\mathrm{mmol} / \mathrm{l})$ to screen for microalbuminuria [40]. If the screening test gave a positive result ( $\geq 2 \mathrm{mg} / \mathrm{mmol}$ ), urinary albumin excretion was measured with immunonephelometry (Behring) using antiserum from Dakopatts (Glostrup, Denmark). Microalbuminuria was defined as an albumin excretion rate of $20 \mu \mathrm{g} / \mathrm{min}$ or more in at least two of the three collected urine samples.

Statistical methods. The results are expressed as mean values and standard deviation unless mentioned otherwise. The effect of insulin and hyperglycaemia on flow values between the two study days, the responses to adenosine infusion, and the interaction of these variables were tested using repeated measures by analysis of variance (procedure Mixed in Statistical Analysis System, SAS Institute, Cary, N.C., USA). For correlation analysis, Spearman's correlation coefficients were calculated. Paired and unpaired $t$ tests were used when appropriate. A $p$ value of less than 0.05 was interpreted as statistically significant. All statistical tests were carried out with SAS statistical analysis system (SAS Institute, Gary, N.C., USA).

\section{Results}

Metabolic and hormonal characteristics of the study subjects. During normoglycaemia plasma glucose, serum free fatty acid concentrations and insulin-stimulated whole body glucose uptake values were similar, 
Table 2. Metabolic and hormonal characteristics of the study subjects

\begin{tabular}{lcc}
\hline & Fasting & During clamp \\
\hline Plasma glucose (mmol/l) & & \\
Non-diabetic & $5.4(0.6)$ & $5.1(0.5)$ \\
DM & $6.8(2.8)$ & $5.8(1.4)$ \\
DM (hg) & $10.8(1.6)^{\mathrm{a}}$ & $10.1(0.5)^{\mathrm{b}}$ \\
S-insulin (mU/l) & & \\
Non-diabetic & $6(2)$ & $63(12)^{\mathrm{c}}$ \\
DM & $17(7)^{\mathrm{d}}$ & $93(27)^{\mathrm{c}}$, $^{\mathrm{d}}$ \\
DM (hg) & $6(3)$ & $80(36)^{\mathrm{c}}$ \\
S-NEFA ( $\mu \mathrm{mol} / \mathrm{l})$ & & \\
Non-diabetic & & \\
DM & $608(347)$ & $100(39)^{* * *}$ \\
DM (hg) & $399(222)$ & $97(64)^{* * *}$ \\
WBGU ( $\mu \mathrm{mol} / \mathrm{kg} \cdot \mathrm{min})$ & $633(373)$ & $83(35)^{* * *}$ \\
Non-diabetic & & \\
DM & & $35.5(11.7)$ \\
DM (hg) & & $30.2(12.2)$ \\
\hline
\end{tabular}

DM, Type I diabetic; hg, during hyperglycaemia; NEFA, nonesterified fatty acids; WBGU, whole body glucose uptake

${ }^{\mathrm{a}} p<0.05,{ }^{\mathrm{b}} p<0.001$ vs normoglycaemia

${ }^{\mathrm{c}} p<0.05$ vs fasting

$\mathrm{d} p<0.05$ vs non-diabetic

but serum insulin concentrations were significantly higher in diabetic patients both in the fasting state and during hyperinsulinaemia when compared to non-diabetic subjects (Table 2 ).

After reduction of insulin dose for 2 days fasting and postprandial plasma glucose values increased significantly according to patients' home measurements $(9.8 \pm 0.7$ vs $6.5 \pm 0.6 \mathrm{mmol} / \mathrm{l}$ and $12.3 \pm 1.8$ vs $8.2 \pm 1.4 \mathrm{mmol} / \mathrm{l}$, hyperglycaemia vs normoglycaemia, fasting and postprandial, $p<0.05$ ). During PET studies plasma glucose was $10.8 \pm 1.6$ vs $6.8 \pm 2.8 \mathrm{mmol} / \mathrm{l}$ before insulin infusion (hyperglycaemia vs normoglycaemia, $p<0.05)$ and $10.1 \pm 0.5$ vs $5.8 \pm 1.4 \mathrm{mmol} / \mathrm{l}(p<0.001)$ during hyperinsulinaemia in the diabetic patients (Table 2). Plasma insulin, serum non-esterified fatty acid concentrations and insulin-stimulated whole body glucose uptake rates were not significantly different during the two PET study days in diabetic patients (Table 2).

Haemodynamic measurements during PET study. Adenosine administration induced a significant increase in heart rate and rate-pressure products both basally and during hyperinsulinaemia and no difference was detected in any of the haemodynamic parameter either at rest or during the PET studies in the all studied subjects (Table 3).

Myocardial blood flow during normoglycaemia. No significant difference was detected in resting myocar-
Table 3. Haemodynamic data during PET in the hyperglycaemia study

\begin{tabular}{|c|c|c|c|}
\hline & \multirow[t]{2}{*}{ Rest } & \multicolumn{2}{|c|}{ Adenosine infusion } \\
\hline & & Saline & Insulin \\
\hline \multicolumn{4}{|c|}{ Heart rate (beats/min) } \\
\hline Non-diabetic & $55(5)$ & $99(12)^{\mathrm{a}}$ & $104(8)^{\mathrm{a}}$ \\
\hline DM & $57(8)$ & $101(8)^{\mathrm{a}}$ & $106(6)^{\mathrm{a}}$ \\
\hline DM (hg) & $58(8)$ & $102(11)^{\mathrm{a}}$ & $103(12)^{\mathrm{a}}$ \\
\hline \multicolumn{4}{|c|}{ Systolic BP (mmHg) } \\
\hline Non-diabetic & $117(10)$ & $118(9)$ & $124(14)$ \\
\hline DM & $117(4)$ & $122(11)$ & $127(8)^{\mathrm{b}}$ \\
\hline DM (hg) & $116(7)$ & $114(12)$ & $118(6)$ \\
\hline \multicolumn{4}{|c|}{ Diastolic BP (mmHg) } \\
\hline Non-diabetic & $66(8)$ & $65(10)$ & $70(10)$ \\
\hline $\mathrm{DM}$ & $72(8)$ & $72(8)$ & $76(5)$ \\
\hline DM (hg) & $69(9)$ & $70(10)$ & $67(7)$ \\
\hline \multicolumn{4}{|c|}{$\mathrm{RPP}(\mathrm{mmHg} / \mathrm{min})$} \\
\hline Non-diabetic & $6418(814)$ & $11,699(1930)^{\mathrm{a}}$ & $12,933(1959)^{a, c}$ \\
\hline $\mathrm{DM}$ & $6502(854)$ & $12,089(795)^{\mathrm{a}}$ & $13,259(630)^{\mathrm{a}, \mathrm{c}}$ \\
\hline DM (hg) & $6764(1138)$ & $11,601(1719)^{\mathrm{a}}$ & $12,226(1801)^{\mathrm{a}}$ \\
\hline
\end{tabular}

DM, Type I diabetic; hg, during hyperglycaemia; RPP, rate pressure product (systolic $\mathrm{BP} \times$ heart rate)

${ }^{\mathrm{a}} p<0.001,{ }^{\mathrm{b}} p<0.05$ vs resting

${ }^{c} p<0.05$ vs adenosine

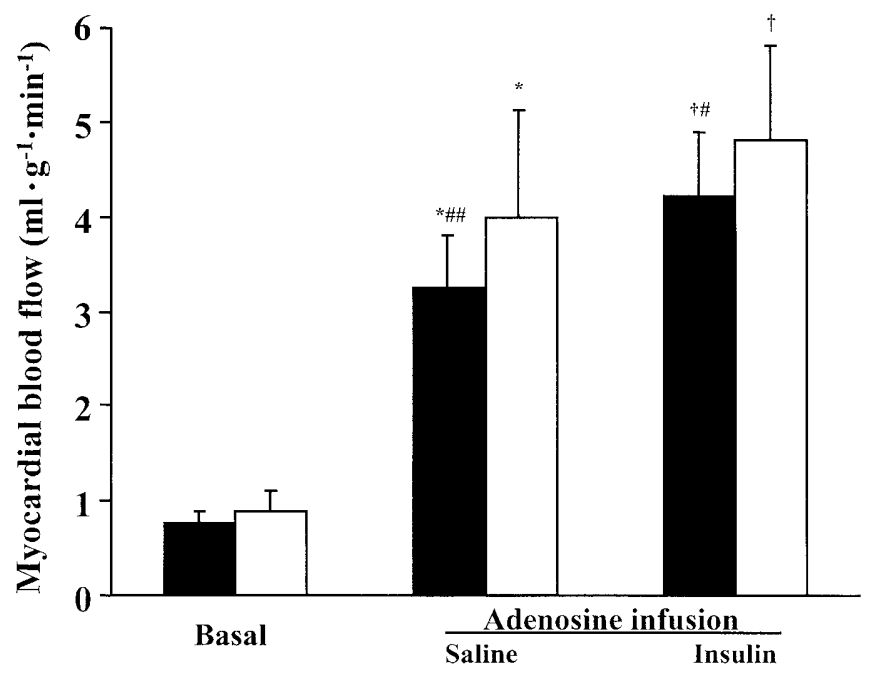

Fig. 2. Myocardial blood flow during basal conditions and during adenosine stimulation without and with simultaneous insulin infusion in diabetic patients (solid square) during normoglycaemia and non-diabetic subjects (open square) (see Fig. 1). ${ }^{*} p<0.001$ vs basal, ${ }^{\dagger} p<0.05$ vs saline, ${ }^{\#} p<0.05,{ }^{\#} p=0.08$ vs non-diabetic

dial blood flow $\left(0.79 \pm 0.13\right.$ vs $0.89 \pm 0.21 \mathrm{ml} \cdot \mathrm{g}^{-1} \cdot \mathrm{min}^{-1}$, diabetic and non-diabetic, NS; Fig. 2). During adenosine induced hyperaemia myocardial blood flow value was $23 \%$ lower in diabetic than non-diabetic subjects $\left(3.09 \pm 0.72\right.$ vs $\left.4.0 \pm 1.13 \mathrm{ml} \cdot \mathrm{g}^{-1} \cdot \mathrm{min}^{-1}, p<0.05\right)$. A significant inverse association was found between adeno- 


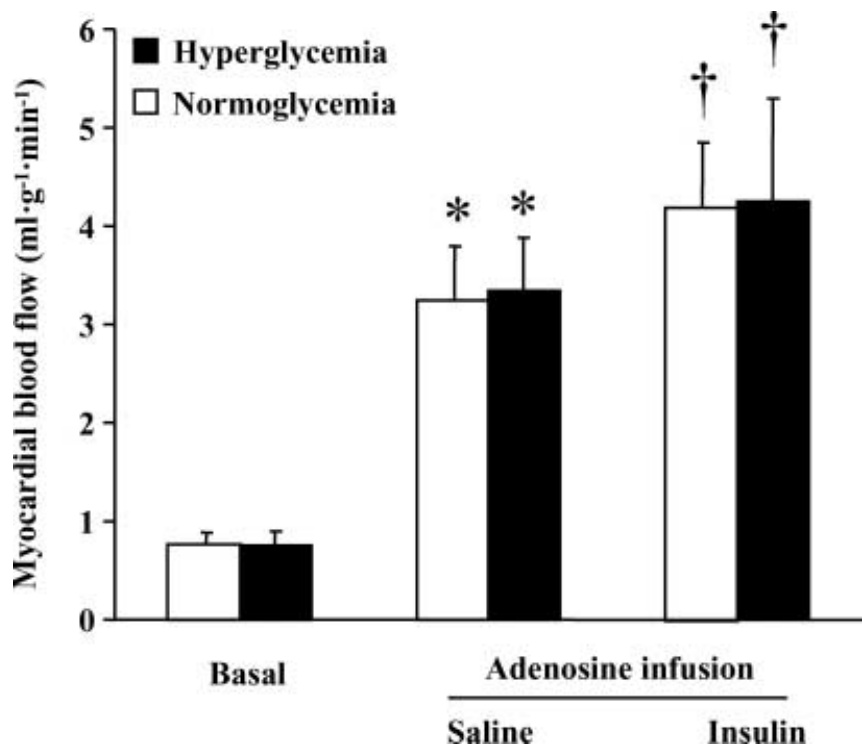

Fig. 3. Myocardial blood flow in diabetic patients during basal conditions and during adenosine stimulation without and with simultaneous insulin infusion during hyperglycaemia (ם) and normoglycaemia ( $\square$ ) (see Fig. 1). ${ }^{*} p<0.001$ vs basal, ${ }^{\dagger} p<0.05$ vs saline

sine stimulated myocardial blood flow and $\mathrm{HbA}_{1 \mathrm{c}}$ in the pooled data $(r=-0.50, p<0.05)$ but not in the diabetic or non-diabetic subjects alone (NS). Insulin increased $(p<0.05)$ adenosine stimulated myocardial blood flow similarly in diabetic $(23 \%)$ and non-diabetic (17\%) subjects (NS between the groups). Hyperaemic flow during insulin infusion tended to be lower in diabetic than non-diabetic subjects $(4.09 \pm 0.75$ vs $4.81 \pm 1.00 \mathrm{ml} \cdot \mathrm{g}^{-1} \cdot \mathrm{min}^{-1}, p=0.08$; Fig. 2 ).

Myocardial blood flow during hyperglycaemia. The effect of hyperglycaemia was studied only in eight out of the nine diabetic patients. Hyperglycaemia did not alter resting myocardial blood flow $\left(0.76 \pm 0.14 \mathrm{ml} \cdot \mathrm{g}^{-1}\right.$. $\left.\mathrm{min}^{-1}\right)$ or adenosine stimulated flow without $\left(3.35 \pm 0.53 \mathrm{ml} \cdot \mathrm{g}^{-1} \cdot \mathrm{min}^{-1}\right)$ or with $\left(4.20 \pm 1.05 \mathrm{ml} \cdot \mathrm{g}^{-1}\right.$. $\mathrm{min}^{-1}$ ) insulin infusion (NS vs normoglycaemia; Fig. 3). During hyperglycaemia insulin infusion increased significantly $(p<0.05)$ and similarly hyperaemic myocardial blood flow than during normoglycaemia in diabetic patients (NS; Fig. 3).

\section{Discussion}

We found that hyperaemic adenosine stimulated myocardial blood flow is already reduced in young patients with uncomplicated Type I diabetes and good glycaemic control. Insulin induces coronary vasodilation similarly in diabetic and non-diabetic subjects and short-term hyperglycaemia appears not to alter myocardial blood flow or abolish insulin-induced vasodilation in Type I diabetic patients.
We have shown that coronary vasoreactivity is reduced in Type I diabetic patients [3]. The previous PET study was carried out during euglycaemic hyperinsulinaemia (serum insulin $\sim 70 \mathrm{mmol} / \mathrm{l}$ ) and we found that hyperaemic myocardial blood flow was $29 \%$ lower in diabetic than non-diabetic subjects $(p<0.05)$. When compared to the present study, diabetic patients of our previous study had slightly poorer glycaemic control $\left(\mathrm{HbA}_{1 \mathrm{c}} 7.4\right.$ vs $\left.8.1 \%\right)$ and some of them had also mild background retinopathy which might contribute to the findings. To study the effect of Type I diabetes, the diabetic patients of this study had no diabetic complications or other diseases such as obesity, hypertension and hyperlipidaemia, which are also known to reduce coronary vasoreactivity $[5,6,7$, $8]$. In this study we demonstrated that coronary vasoreactivity is already reduced in young patients with uncomplicated Type I diabetes and good glycaemic control. This could represent an early precursor of future coronary artery disease in these diabetic patients.

In our study, insulin's vasodilatory effects were measured during adenosine infusion. A significant part of adenosine-induced vasodilation is endothelium-dependent [41]. In contrast to resting condition where flow and myocardial work (oxygen consumption) are tightly coupled, during adenosine stimulation metabolic control of myocardial blood flow is lost but endothelial and neurogenic controls are still functional. In addition, the flow is directly dependent on blood pressure and modulated by mechanical forces in the myocardial wall [42]. At resting conditions it seems to take at least $2 \mathrm{~h}$ for physiological hyperinsulinaemia to induce significant vasodilation in myocardial vasculature $[11,43]$. However, in peripheral vasculature insulin, possibly by potentiating endothelium-dependent vasodilation, has been found to enhance the effect of endothelium-dependent vasodilators before any changes in basal blood flow can be detected [44, 45]. Accordingly physiological hyperinsulinaemia for $1 \mathrm{~h}$ enhances adenosine-stimulated myocardial blood flow in healthy humans $[14,46]$. This synergistic effect of adenosine and insulin on myocardial perfusion demonstrates that adenosine alone is not able to induce "maximal" hyperaemia.

Intravenous insulin therapy has been shown to be beneficial in the treatment of short-term myocardial infarction especially in diabetic patients [19]. It has been shown using SPECT that glucose-potassium-insulin infusion therapy improves regional myocardial perfusion and function mainly in segments adjacent to the recently infarcted area [47]. Several metabolic mechanisms, such as changes in glucose $[15,16]$ and non-esterified fatty acid metabolism [17, 18], could explain it. In this study, we showed that insulin induces coronary vasodilation similarly in diabetic and nondiabetic subjects. Therefore, insulin's vasodilatory effects on myocardial blood flow might also, at least in partly, contribute to this beneficial effect of intensive 
insulin therapy in the treatment of diabetic patients with acute myocardial infarction. In skeletal muscle in the two studies available insulin induced vasodilation was reduced in one study [48] but was normal in another study [49] in Type I diabetic patients.

Recently, it has been found that during chronic hyperglycaemia, endothelial cells' metalloproteinases are activated, indicating a mechanism by which poor glycaemic control could increase the risk for atherosclerotic complications [50]. However, short-term hyperglycaemia (24-h) was not able to induce the same alteration [50]. In this study, we studied the effect of high plasma glucose concentrations on myocardial perfusion in Type I diabetic patients. We found that hyperglycaemia for two days did not alter any of the flow values or abolish insulin induced vasodilation in diabetic patients. The effect of hyperglycaemia was studied only in diabetic patients because a longer period of hyperglycaemia (e.g. 2 days) is not feasible in non-diabetic subjects. In peripheral vasculature the effects of acute hyperglycaemia on blood flow are controversial because in one study hyperglycaemia blunted insulin induced vasodilation [48] while in another more recent study hyperglycaemia did not alter blood flow or its response to insulin [49].

Poor glycaemic control is associated with microvascular complications in Type I diabetic patients [51, 52, 53]. Chronic hyperglycaemia might also increase the risk for coronary artery disease by many mechanisms, such as abnormalities in lipoprotein particle composition, irreversible glycation of proteins in the arterial wall [54], acceleration of thrombus formation [54] and oxidation of lipoproteins [55] or worsening of insulin resistance and hyperinsulinaemia [56]. Consistent with that many $[20,21,22,23]$ but not all studies $[57,58]$ have found that higher $\mathrm{HbA}_{1 \mathrm{c}}$ is a predictor for macrovascular complications. We found that $\mathrm{HbA}_{1 \mathrm{c}}$ was inversely associated with hyperaemic adenosine stimulated myocardial blood flow in the pooled data but not in the diabetic or non-diabetic subjects alone. Thus, we cannot clearly explain the role of chronic hyperglycaemia on coronary vasoreactivity in this study. This important issue needs further studies including diabetic patients with poor glycaemic control because in our previous PET study [3] diabetic patients with poorer glycaemic control than in this study also had more reduced coronary vasoreactivity.

In summary, the present data demonstrate that hyperaemic adenosine-stimulated myocardial blood flow is already reduced in young otherwise healthy patients with uncomplicated Type I diabetes and good glycaemic control. This could represent an early precursor of future coronary artery disease in these diabetic patients. Insulin has similar vasodilative effects on coronary arteries in diabetic and non-diabetic subjects which might contribute to the known beneficial effects of intensive insulin therapy on myocardial ischaemia in diabetic patients. Short-term hyperglycaemia appears not to alter myocardial blood flow nor abolish insulin-induced vasodilation in Type I diabetic patients.

Acknowledgements. The study was financially supported by the grants of EVO from the Turku University Hospital, Finnish Foundation for Cardiovascular Research, the Novo Nordisk Foundation, Research Foundation of Orion Corporation and Academy of Finland. We thank the staff of Turku PET Centre for their excellent technical assistance.

\section{References}

1. Grundy SM, Benjamin IJ, Burke GL et al. (1999) Diabetes and cardiovascular disease: a statement for healthcare professionals from the American Heart Association. Circulation 100:1134-1146

2. Nitenberg A, Valensi P, Sachs R, Dali M, Aptecar E, Attali JR (1993) Impairment of coronary vascular reserve and ACh-induced coronary vasodilation in diabetic patients with angiographically normal coronary arteries and normal left ventricular systolic function. Diabetes 42:1017-1025

3. Pitkanen OP, Nuutila P, Raitakari OT et al. (1998) Coronary flow reserve is reduced in young men with IDDM. Diabetes 47:248-254

4. Di Carli MF, Bianco-Batlles D, Landa ME et al. (1999) Effects of autonomic neuropathy on coronary blood flow in patients with diabetes mellitus. Circulation 100:813-819

5. Pitkanen OP, Raitakari OT, Niinikoski H et al. (1996) Coronary flow reserve is impaired in young men with familial hypercholesterolemia. J Am Coll Cardiol 28:1705-1711

6. Laine H, Raitakari OT, Niinikoski H et al. (1998) Early impairment of coronary flow reserve in young men with borderline hypertension. J Am Coll Cardiol 32:147-153

7. Stevens MJ, Raffel DM, Allman KC et al. (1998) Cardiac sympathetic dysinnervation in diabetes: implications for enhanced cardiovascular risk. Circulation 98:961-968

8. Akasaka T, Yoshida K, Hozumi T et al. (1997) Retinopathy identifies marked restriction of coronary flow reserve in patients with diabetes mellitus. J Am Coll Cardiol 30:935941

9. Baron AD (1994) Hemodynamic actions of insulin. Am J Physiol 267:E187-E202

10. Laakso M, Edelman SV, Brechtel G, Baron AD (1990) Decreased effect of insulin to stimulate skeletal muscle blood flow in obese man. A novel mechanism for insulin resistance. J Clin Invest 85:1844-1852

11. Utriainen T, Malmstrom R, Makimattila S, Yki-Jarvinen $H$ (1995) Methodological aspects, dose-response characteristics and causes of interindividual variation in insulin stimulation of limb blood flow in normal subjects. Diabetologia 38:555-564

12. Sobrevia L, Nadal A, Yudilevich DL, Mann GE (1996) Activation of L-arginine transport (system y+) and nitric oxide synthase by elevated glucose and insulin in human endothelial cells. J Physiol (Lond) 490:775-781

13. Scherrer U (1995) Insulin and the regulation of cardiovascular system: role of the L-arginine nitric oxide pathway and the sympathetic nervous system. In: Lüscher TE (ed) The endotheliuma in cardiovascular disease. Springer Verlag, Heidelberg, pp 108-128

14. Laine H, Nuutila P, Luotolahti M et al. (2000) Insulin-induced increment of coronary flow reserve is not abolished 
by dexamethasone in healthy young men. J Clin Endocrinol Metab 85:1868-1873

15. Fava S, Aquilina O, Azzopardi J, Agius MH, Fenech FF (1996) The prognostic value of blood glucose in diabetic patients with acute myocardial infarction. Diabet Med 13:80-83

16. Maki M, Luotolahti M, Nuutila P et al. (1996) Glucose uptake in the chronically dysfunctional but viable myocardium. Circulation 93:1658-1666

17. Maki MT, Haaparanta MT, Luotolahti MS et al. (1997) Fatty acid uptake is preserved in chronically dysfunctional but viable myocardium. Am J Physiol 273:H2473-H2480

18. Oliver MF, Opie LH (1994) Effects of glucose and fatty acids on myocardial ischaemia and arrhythmias. Lancet 343 : $155-158$

19. Malmberg K, Norhammar A, Wedel H, Ryden L (1999) Glycometabolic state at admission: important risk marker of mortality in conventionally treated patients with diabetes mellitus and acute myocardial infarction: long-term results from the Diabetes and Insulin-Glucose Infusion in Acute Myocardial Infarction (DIGAMI) study. Circulation 99:2626-2632

20. Kuusisto J, Mykkanen L, Pyorala K, Laakso M (1994) NIDDM and its metabolic control predict coronary heart disease in elderly subjects. Diabetes 43:960-967

21. Klein R (1995) Hyperglycemia and microvascular and macrovascular disease in diabetes. Diabetes Care 18:258268

22. Lehto S, Ronnemaa T, Pyorala K, Laakso M (1999) Poor glycemic control predicts coronary heart disease events in patients with type 1 diabetes without nephropathy. Arterioscler Thromb Vasc Biol 19:1014-1019

23. Singer DE, Nathan DM, Anderson KM, Wilson PW, Evans JC (1992) Association of HbA1c with prevalent cardiovascular disease in the original cohort of the Framingham Heart Study. Diabetes 41:202-208

24. Makimattila S, Virkamaki A, Groop PH et al. (1996) Chronic hyperglycemia impairs endothelial function and insulin sensitivity via different mechanisms in insulindependent diabetes mellitus. Circulation 94:1276-1282

25. Johnstone MT, Creager SJ, Scales KM, Cusco JA, Lee BK, Creager MA (1993) Impaired endothelium-dependent vasodilation in patients with insulin- dependent diabetes mellitus. Circulation 88:2510-2516

26. Giugliano D, Marfella R, Coppola L et al. (1997) Vascular effects of acute hyperglycemia in humans are reversed by L- arginine. Evidence for reduced availability of nitric oxide during hyperglycemia. Circulation 95:1783-1790

27. Araujo LI, Lammertsma AA, Rhodes CG et al. (1991) Noninvasive quantification of regional myocardial blood flow in coronary artery disease with oxygen-15-labeled carbon dioxide inhalation and positron emission tomography. Circulation 83:875-885

28. Pitkanen OP, Raitakari OT, Ronnemaa T et al. (1997) Influence of cardiovascular risk status on coronary flow reserve in healthy young men. Am J Cardiol 79:1690-1692

29. Dayanikli F, Grambow D, Muzik O, Mosca L, Rubenfire M, Schwaiger M (1994) Early detection of abnormal coronary flow reserve in asymptomatic men at high risk for coronary artery disease using positron emission tomography. Circulation 90:808-817

30. Uren NG, Melin JA, De Bruyne B, Wijns W, Baudhuin T, Camici PG (1994) Relation between myocardial blood flow and the severity of coronary- artery stenosis. N Engl J Med 330:1782-1788

31. DeFronzo RA, Tobin JD, Andres R (1979) Glucose clamp technique: a method for quantifying insulin secretion and resistance. Am J Physiol 237:E214-E223
32. Crouzel C, Clark J, Brihaye C et al. (1993) Radiochemistry automation for PET. In: Stöckling G, Pike V (eds) Radiopharmaceuticals for positron emission tomography. Kluwer Academic Publishers, Dordrecht, pp 45-90

33. Alenius S, Ruotsalainen U (1997) Bayesian image reconstruction for emission tomography based on median root prior. Eur J Nucl Med 24:258-265

34. Iida H, Kanno I, Takahashi A et al. (1988) Measurement of absolute myocardial blood flow with $\mathrm{H} 215 \mathrm{O}$ and dynamic positron-emission tomography. Strategy for quantification in relation to the partial-volume effect. Circulation 78: 104-115

35. Iida H, Takahashi A, Tamura Y, Ono Y, Lammertsma AA (1995) Myocardial blood flow: comparison of oxygen-15water bolus injection, slow infusion and oxygen-15-carbon dioxide slow inhalation. J Nucl Med 36:78-85

36. Iida H, Rhodes CG, de Silva R et al. (1992) Use of the left ventricular time-activity curve as a noninvasive input function in dynamic oxygen-15-water positron emission tomography. J Nucl Med 33:1669-1677

37. Holewski JJ, Stess RM, Graf PM, Grunfeld C (1988) Aesthesiometry: quantification of cutaneous pressure sensation in diabetic peripheral neuropathy. J Rehabil Res Dev 25: $1-10$

38. Kadish A, Little R, Sternberg J (1968) A new and rapid method for the determination of glucose by measurement of rate of oxygen consumption. Clin Chem 14:116-131

39. Friedewald WT, Levy RI, Fredrickson DS (1972) Estimation of the concentration of low-density lipoprotein cholesterol in plasma, without use of the preparative ultracentrifuge. Clin Chem 18:499-502

40. Scheid DC, McCarthy LH, Lawler FH, Hamm RM, Reilly KE (2001) Screening for microalbuminuria to prevent nephropathy in patients with diabetes: a systematic review of the evidence. J Fam Pract 50:661-668

41. Buus NH, Bottcher M, Hermansen F, Sander M, Nielsen TT, Mulvany MJ (2001) Influence of nitric oxide synthase and adrenergic inhibition on adenosine-induced myocardial hyperemia. Circulation 104:2305-2310

42. Opie LH (1998) The Heart. 3nd edn. Lippincott-Raven Publishers, New York

43. Ferrannini E, Santoro D, Bonadonna R, Natali A, Parodi O, Camici PG (1993) Metabolic and hemodynamic effects of insulin on human hearts. Am J Physiol 264:E308-E315

44. Steinberg HO, Chaker H, Leaming R, Johnson A, Brechtel $\mathrm{G}$, Baron AD (1996) Obesity/insulin resistance is associated with endothelial dysfunction. Implications for the syndrome of insulin resistance. J Clin Invest 97:2601-2610

45. Taddei S, Virdis A, Mattei P, Natali A, Ferrannini E, Salvetti A (1995) Effect of insulin on acetylcholine-induced vasodilation in normotensive subjects and patients with essential hypertension. Circulation 92:2911-2918

46. Sundell J, Nuutila P, Laine H et al. (2002) Dose-dependent vasodilating effects of insulin on adenosine-stimulated myocardial blood flow. Diabetes (in press)

47. Marano L, Bestetti A, Lomuscio A et al. (2000) Effects of infusion of glucose-insulin-potassium on myocardial function after a recent myocardial infarction. Acta Cardiol 55: 9-15

48. Baron AD, Laakso M, Brechtel G, Edelman SV (1991) Mechanism of insulin resistance in insulin-dependent diabetes mellitus: a major role for reduced skeletal muscle blood flow. J Clin Endocrinol Metab 73:637-643

49. Makimattila S, Virkamaki A, Malmstrom R, Utriainen T, Yki-Jarvinen H (1996) Insulin resistance in type I diabetes mellitus: a major role for reduced glucose extraction. J Clin Endocrinol Metab 81:707-712 
50. Uemura S, Matsushita H, Li W et al. (2001) Diabetes mellitus enhances vascular matrix metalloproteinase activity: role of oxidative stress. Circ Res 88:1291-1298

51. D'Antonio JA, Ellis D, Doft BH et al. (1989) Diabetes complications and glycemic control. The Pittsburgh Prospective Insulin-Dependent Diabetes Cohort Study Status Report after 5 yr of IDDM. Diabetes Care 12:694-700

52. Klein R, Klein BE, Moss SE, Davis MD, DeMets DL (1988) Glycosylated hemoglobin predicts the incidence and progression of diabetic retinopathy. JAMA 260:2864-2871

53. Wolffenbuttel BH (1993) The DCCT: "metabolic control matters". Diabetes Control and Complications Trial. Neth J Med 43:241-245

54. Colwell JA (1993) Vascular thrombosis in type II diabetes mellitus. Diabetes 42:8-11
55. Lyons TJ (1992) Lipoprotein glycation and its metabolic consequences. Diabetes 41 [Suppl 2]:67-73

56. Ducimetiere P, Eschwege E, Papoz L, Richard JL, Claude JR, Rosselin G (1980) Relationship of plasma insulin levels to the incidence of myocardial infarction and coronary heart disease mortality in a middle-aged population. Diabetologia 19:205-210

57. Deckert T, Yokoyama H, Mathiesen E et al. (1996) Cohort study of predictive value of urinary albumin excretion for atherosclerotic vascular disease in patients with insulin dependent diabetes. BMJ 312:871-874

58. LLoyd CE, Kuller LH, Ellis D, Becker DJ, Wing RR, Orchard TJ (1996) Coronary artery disease in IDDM. Gender differences in risk factors but not risk. Arterioscler Thromb Vasc Biol 16:720-726 